\title{
A Cadaveric Morphometric Study of Lumbar Vertebrae in Zimbabwean Adult Males
}

\author{
Maimoona Khan ${ }^{1}$, Basira Delland Zvikomborero ${ }^{1}$ \\ ${ }^{1}$ Department of Anatomy, College of Health Sciences, University of Zimbabwe, Harare Zimbabwe
}

\begin{abstract}
A BSTRACT
Background: Transpedicular screw fixation has been widely used for spinal reconstruction because of its good fusion results. However, pedicle walls can be damaged during fixation if diameter of the screw is too large or screw is misplaced. Knowledge of the morphometric dimensions of the pedicle is thus important for effective fixation and to avoid complications. The main objective of this study was to measure the Pedicle Transverse Diameter (PTD), Pedicle Vertical Diameter (PVD) and chord length of male adult cadavers from Zimbabwean population.

Material and Methods: It was a descriptive cross-sectional study carried out at the Department of Anatomy, University of Zimbabwe College of Health Sciences, Harare Zimbabwe, from June 2019 to December 2019. The lumbar vertebrae from 15 adult male cadavers were dissected out and Pedicle Transverse Diameter (PTD), Pedicle Vertical Diameter (PVD) and chord length was measured and compared (on right and left sides), using a Vernier caliper. The statistical analysis was done using SPSS version 20.0., with data expressed as means, standard deviation and ranges. Student's t-test was used to estimate the difference in pedicle dimensions of the right and left sides of the lumbar vertebrae.

Results: There was an insignificant difference between pedicle dimensions (PTD and PVD) of the right and left sides ( $P$ $>$.05). PTD steadily increased from vertebral level L1 to $L 5$ followed by an abrupt increase at L5. PVD gradually decreased from $L 1$ to $L 5$ level. The chord length increased from a minimum at $L 1$ to reach a maximum at $L 3$ and then again decreased to $L 5$ level.

Conclusions: Pedicle dimensions of the Zimbabwean population differ from those reported in previous studies for other population groups and can be useful while performing pedicle screw fixation for lumbar vertebral fractures. A screw length of $40-45 \mathrm{~mm}$ should be used for lumbar transpedicular screw fixation with minimal risk of implant failure in Zimbabwean population.

Key words: Chord length, Lumbar vertebrae, Pedicle transverse diameter, Pedicle vertical diameter

$\begin{array}{ll}\text { Authors' Contribution: } & \text { Correspondence: } \\ \text { 1-2Conception; Literature } \quad \text { research; } & \text { Maimoona Khan }\end{array}$

manuscript design and drafting; Critical Email:maimoonakhan@hotmail.com

analysis and manuscript review; Data

analysis; Manuscript Editing.

Article info:

Received: December 25, 2019

Accepted: December 22, 2020
\end{abstract}

Cite this article. Khan M, Zvikomborero BD. A Cadaveric Morphometric Study of Lumbar Vertebrae in Zimbabwean Adult Males. J Islamabad Med Dental Coll. 2020; 9(4): 291-297. Doi: 10.35787/jimdc.v9i4.479

\section{Introduction}

The lumbar vertebral column consists of five vertebrae numbered from L1 to L5, articulating at inter-vertebral joints. ${ }^{1}$ These vertebrae have a large
Funding Source: Nil

Conflict of Interest: Nil kidney-shaped body for support and weight bearing. During weight transmission, lumbar vertebrae support much of the weight of the upper body and 
are thus more prone to degenerative changes with advancing age. Therefore, surgical interventions are most commonly performed in this region to alleviate symptoms of backache caused by arthritic changes, deformities and fractures. ${ }^{2}$

The pedicles of a lumbar vertebrae arise near the upper border of the posterolateral aspect of the body. They are large, stout and strong, consisting almost entirely of cortical bone with a small core of cancellous bone. ${ }^{3}$ Research in an Indian population has shown that pedicle width increases from L1 level and reaches maximum at $\mathrm{L} 5$, whereas pedicle height is maximum in the L1 and L2 vertebrae, then decreases from L3 down to L5. ${ }^{4}$

Transpedicular screw fixation of the lumbar vertebrae is performed surgically in patients with thoraco lumbar vertebral fractures, spondylolisthesis, kyphosis, posterolateral synostosis, vertebral collapse and canal stenosis. ${ }^{5}$ These screws are commonly used for posterior fixation in spinal instability, but their insertion remains challenging. There is a misplacement rate of up to $11 \%$ even with navigation techniques. The diameter of the screw is determined by the horizontal diameter of the pedicle. ${ }^{6}$ Successful fixation depends on detailed knowledge of the size and dimensions of the pedicles. The minimum width of the pedicle is an important factor to consider during screw selection. A screw of larger diameter can damage the pedicle and may end up causing injuries, ${ }^{7}$ like dural tears, leakage of cerebrospinal fluid and damage to spinal nerve roots. ${ }^{8}$

Multiple researches have reported variations in pedicle morphometry between different ethnic groups. ${ }^{9}$ Imaging techniques such as C-arm fluoroscopy can be employed to enhance accuracy during pedicle screw placement. However, this exposes both patient and surgeon to radiations along with increased cost and operative time. ${ }^{10} \mathrm{~A}$ detailed study of dimensions of the pedicles of lumbar vertebrae is thus essential for proper fixation without complications. Therefore, the main objective of this study was to measure the Pedicle Transverse Diameter (PTD), Pedicle Vertical Diameter (PVD) and cord length of male adult cadavers from Zimbabwean population.

\section{Material and Methods}

This descriptive cross-sectional study was carried out in the Department of Anatomy, University of Zimbabwe College of Health Sciences Harare, Zimbabwe. The duration of the study was 6 months, from June 2019 to December 2019. The sample consisted of 15 adult black Zimbabwean male cadavers. ${ }^{11}$ Non probability convenience sampling was used, where cadavers were selected according to their accessibility and proximity to the researcher. Approval of Joint Research Ethics Committee of the University of Zimbabwe was taken before carrying out the study. Adult black male cadavers, between the age group of 24 to 40 years with no obvious vertebral deformities were included in the study. Male cadavers with scoliosis or other gross vertebral malformations, injuries of lumbar vertebrae, Caucasians, females and children were excluded from this study. Osteoporotic changes were not ruled out, since only male cadavers, aged between 25 to 40 years were considered in this study.

Embalmed human cadavers were dissected using posterior approach to the lumbar spine. With the cadaver in prone position, the postaxial musculature was retracted as far as the tips of the transverse processes with scalpels and retractors. The lumbar vertebrae were then removed by cutting through intervertebral joints. After removal, the vertebrae were heated in a macerating tank for 36 hours at a constant temperature of $70^{\circ} \mathrm{C}$. The remaining soft tissues were removed by manual dissection ${ }^{12}$ and the vertebrae were air dried. The pedicle width (transverse diameter), pedicle height (vertical diameter) and chord length were measured on both 
sides of the lumbar vertebrae by using a sliding Vernier caliper ${ }^{13}$ (Figures $1 \mathrm{~A}$ and $\mathrm{B}$ ). Pedicle height was measured at two sites; mid pedicle and at root of the pedicle (junction of pedicle with the vertebral body). ${ }^{13}$ Chord length was measured from the posterior cortical entry point of the pedicle to the anterior vertebral cortex along the axis of the pedicle. ${ }^{13}$

Statistical analysis was done by IBM-SPSS version 20.0. Means, standard deviations and ranges were calculated. Student's t-test was used to estimate the difference in pedicle dimensions of the right and left sides.

\begin{tabular}{|c|c|c|c|c|c|}
\hline $\begin{array}{l}\text { Vertebral } \\
\text { Level }\end{array}$ & Values & $\begin{array}{l}\text { Left Pedicle Transverse } \\
\text { Diameter }(\mathrm{mm})\end{array}$ & $\begin{array}{c}\text { Right Pedicle Transverse } \\
\text { Diameter (mm) }\end{array}$ & $P$-value* & Pooled Mean \\
\hline \multirow{3}{*}{ L1 } & Mean & 8.08 & 8.04 & \multirow{3}{*}{.766} & 8.06 \\
\hline & SD & 1.45 & 1.32 & & 1.36 \\
\hline & Range & $5-9.8$ & $5.6-9.8$ & & $5-9.08$ \\
\hline \multirow{3}{*}{ L2 } & Mean & 8.22 & 8.13 & \multirow{3}{*}{.673} & 8.18 \\
\hline & SD & 1.14 & 1.28 & & 1.19 \\
\hline & Range & $6.25-9.6$ & $5.25-9.65$ & & $5.25-9.65$ \\
\hline \multirow{3}{*}{ L3 } & Mean & 9.78 & 9.75 & \multirow{3}{*}{.877} & 9.81 \\
\hline & SD & 1.05 & 1.32 & & 1.17 \\
\hline & Range & 7.6-11.4 & $6.85-12$ & & $6.85-12$ \\
\hline \multirow{3}{*}{ L4 } & Mean & 11.49 & 11.34 & \multirow{3}{*}{.535} & 11.41 \\
\hline & SD & 1.37 & 1.26 & & 1.29 \\
\hline & Range & $9.8-13.6$ & $8.7-13.1$ & & $8.7-13.6$ \\
\hline \multirow{3}{*}{ L5 } & Mean & 18.36 & 18.45 & \multirow{3}{*}{.807} & 18.41 \\
\hline & SD & 2.13 & 2.46 & & 2.25 \\
\hline & Range & $13.7-21$ & $13.2-22.15$ & & $13.2-22.15$ \\
\hline
\end{tabular}

${ }^{*} P$-value $<.05$ was considered statistically significant

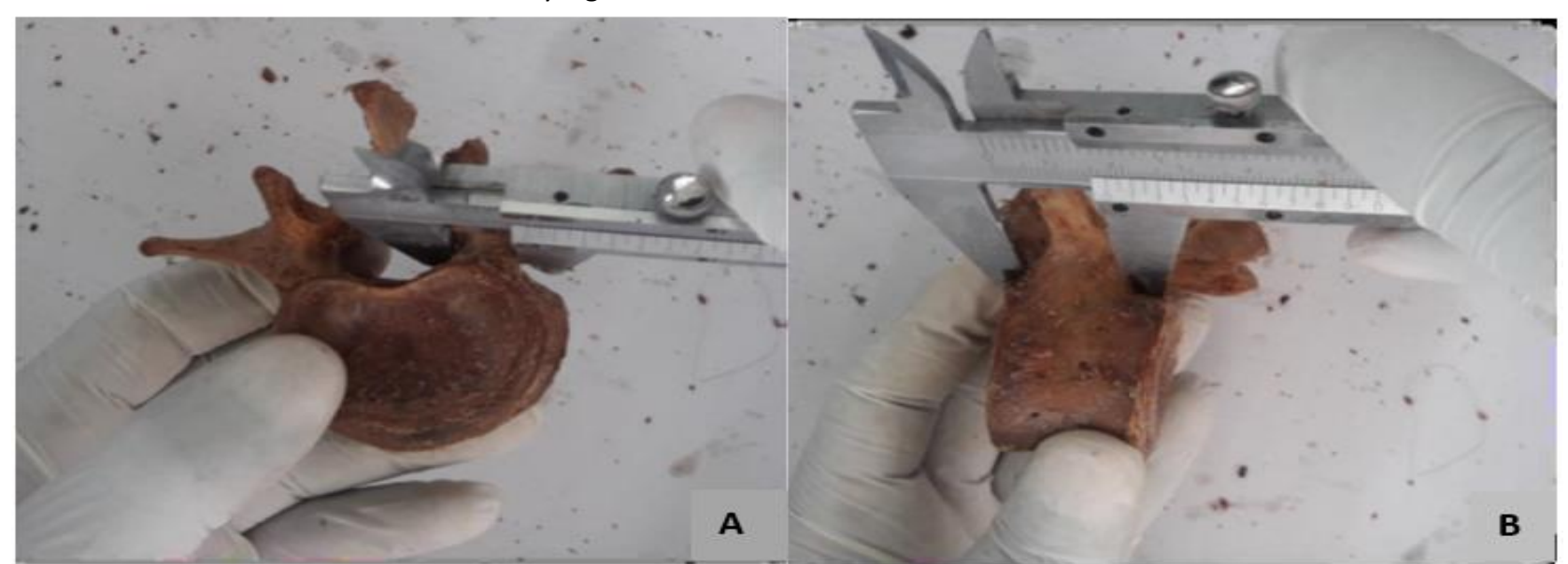

Figure 1: Photograph of lumbar vertebra showing pedicle measurement using sliding Vernier caliper. A: Pedicle transverse diameter, B: Pedicle vertical diameter. 


\begin{tabular}{|c|c|c|c|c|c|}
\hline $\begin{array}{l}\text { Vertebral } \\
\text { Level }\end{array}$ & Values & $\begin{array}{c}\text { Left Pedicle Vertical } \\
\text { Diameter }(\mathrm{mm})\end{array}$ & $\begin{array}{l}\text { Right Pedicle Vertical } \\
\text { Diameter }(\mathrm{mm})\end{array}$ & $P$-value ${ }^{*}$ & Pooled Mean \\
\hline \multirow{3}{*}{ L1 } & Mean & 16.28 & 16.57 & \multirow{3}{*}{.137} & 16.42 \\
\hline & SD & 1.46 & 1.37 & & 1.40 \\
\hline & Range & $14.6-19.9$ & $14.5-19.3$ & & $14.5-19.9$ \\
\hline \multirow{3}{*}{ L2 } & Mean & 15.54 & 15.85 & \multirow{3}{*}{.172} & 15.69 \\
\hline & SD & 1.2 & 1.04 & & 1.11 \\
\hline & Range & $14-18.6$ & $14.4-18.5$ & & $14-18.6$ \\
\hline \multirow{3}{*}{ L3 } & Mean & 15.36 & 15.54 & \multirow{3}{*}{.415} & 15.45 \\
\hline & SD & 1.07 & 1.09 & & 1.07 \\
\hline & Range & $14.1-18.5$ & $13.1-18.2$ & & $13.1-18.5$ \\
\hline \multirow{3}{*}{ L4 } & Mean & 14.99 & 15.18 & \multirow{3}{*}{.45} & 15.09 \\
\hline & SD & 1.15 & 0.98 & & 1.06 \\
\hline & Range & $13.5-17.7$ & $13.6-17$ & & $13.5-17.7$ \\
\hline \multirow{3}{*}{ L5 } & Mean & 14.68 & 15.21 & \multirow{3}{*}{.173} & 14.94 \\
\hline & SD & 1.32 & 1.52 & & 1.42 \\
\hline & Range & $12.4-16.8$ & $12.4-18.8$ & & $12.40-18.8$ \\
\hline
\end{tabular}

${ }^{*} P$-value $<.05$ was considered statistically significant

\begin{tabular}{|c|c|c|c|c|c|}
\hline \multicolumn{6}{|c|}{ Table III: Comparison of the mean chord length of the right and left sides of the lumbar vertebrae } \\
\hline $\begin{array}{l}\text { Vertebral } \\
\text { Level }\end{array}$ & Values & Left Chord Length (mm) & Right Chord Length (mm) & $P$-value* & Pooled Mean \\
\hline \multirow{3}{*}{ L1 } & Mean & 46.29 & 46.34 & \multirow{3}{*}{.682} & 46.31 \\
\hline & SD & 1.18 & 0.97 & & 1.06 \\
\hline & Range & 43.7-48.2 & 44.3-47.5 & & $43.7-50$ \\
\hline \multirow{3}{*}{ L2 } & Mean & 46.91 & 47.86 & \multirow{3}{*}{.731} & 47.39 \\
\hline & SD & 0.87 & 1.2 & & 1.14 \\
\hline & Range & $45.4-48.4$ & $45.8-50$ & & $45.4-50$ \\
\hline \multirow{3}{*}{ L3 } & Mean & 48.33 & 48.63 & \multirow{3}{*}{.891} & 48.48 \\
\hline & SD & 1.07 & 1 & & 1.03 \\
\hline & Range & $46.4-50$ & $46.8-50.3$ & & $46.4-50.3$ \\
\hline \multirow{3}{*}{ L4 } & Mean & 47.89 & 47.17 & \multirow{3}{*}{.632} & 47.53 \\
\hline & SD & 0.95 & 1.27 & & 1.16 \\
\hline & Range & $46.0-49.2$ & $44.6-48.9$ & & $44.6-48.9$ \\
\hline \multirow{3}{*}{ L5 } & Mean & 47.36 & 46.85 & \multirow{3}{*}{.415} & 47.1 \\
\hline & SD & 1.19 & 1.29 & & 1.24 \\
\hline & Range & $44.7-49.4$ & $44.5-49.3$ & & $44.5-49.4$ \\
\hline
\end{tabular}

${ }^{*} P$-value $<.05$ was considered statistically significant

\section{Discussion}

Lumbar region of the vertebral column plays an essential role in weight transmission and also permits a wide range of movement. Pedicles of the posterior arch of the vertebra are important in transmission of force between anterior and posterior elements of the vertebrae. ${ }^{14}$ Any deformity of the pedicles can affect the weight transmission dynamics and can also compress neural structure. Pedicle screw fixation is a successful method of spine stabilization and has shown promising fusion results. The insertion of the screws remains challenging due to variations in width and height of pedicles and the proximity of the spinal nerve roots. PTD is an important factor that 
determines the diameter of the screw used. Variations in pedicle morphometry has been reported in people of different ethnic groups. ${ }^{12}$

The present study showed that there is a steady increase in the pedicle transverse diameter from L1 to L4 followed by an abrupt increase at L5 level. This is consistent with the findings in studies done on Korean, American, and Indian populations. ${ }^{15-17} \mathrm{~A}$ study done in the Saudi population showed a higher PTD between $\mathrm{L} 1$ and $\mathrm{L} 4$ and a smaller diameter of $\mathrm{L} 5$ as compared to other populations. Although there is a general increase in PTD, there is no abrupt increase in PTD at L5 level. ${ }^{18}$ In the present study, the PTD is smaller than that found in American, Indian and Saudi populations. ${ }^{16-18}$ In two studies conducted in an Indian population, ${ }^{19,20}$ there was a general increase in PTD from L1 to L5 except at L2 level where minimum increase was seen.

In cross-section, PTD is the minimum thickness of the pedicle and hence dictates the maximum pedicle screw diameter. A study conducted in USA showed that PTD in the upper and lower lumbar vertebral levels was greater than $5 \mathrm{~mm}$ and $7 \mathrm{~mm}$, thus pedicle screws of diameter $5 \mathrm{~mm}$ and $7 \mathrm{~mm}$ could be used in these regions respectively. ${ }^{21}$ Based on the results obtained in the present study, where mean pedicle width is greater than $7 \mathrm{~mm}$ and $9 \mathrm{~mm}$ in the upper and lower lumbar regions respectively, it can be concluded that the maximum diameter of pedicle screw instrumented in the lumbar regions should be $7 \mathrm{~mm}$ and $9 \mathrm{~mm}$ in the respective vertebral segments.

The maximum PVD was obtained at L1 level and there was a steady decrease down to L5. This trend is similar to the ones found by the other researchers. ${ }^{16,17,21}$ However, data of Saudi population showed minimum PVD at vertebral level L2 and a maximum at L5. ${ }^{18}$ In cross section, the vertebral pedicle is oval in shape. It has been established that the pedicle vertical diameter is significantly greater than the transverse diameter. ${ }^{22}$ Therefore, from a practical point of view, PVD carries lesser significance in selecting the pedicle screw diameter than PTD, and our study conforms to this theory.

In the present study, maximum chord length was recorded at $\mathrm{L} 3$ level and the minimum at L1. In a Turkish study, the longest chord length was obtained at level L1 and the shortest was at vertebral level $L 5$, lower than those obtained in the current study. ${ }^{22}$ Chord length determines the maximum length of any screw that can be safely used for pedicular screw fixation without anterior cortex violation. ${ }^{23}$ Three other studies (American and Indian) reported that the longest chord length was at L2 while the shortest was at vertebral level L5. ${ }^{16,24,25}$ The screw length should include $50 \%$ of the vertebral body in order to minimize instrument failure while allowing for effective screw fixation. A significantly longer screw can perforate the anterior cortex of the vertebral body causing damage to visceral organs and major blood vessels. ${ }^{16}$ Currently, 40-43 $\mathrm{mm}$ screw length is used in Zimbabwe, but the results of present study showed that a screw length of $40-45 \mathrm{~mm}$ can be used in the lumbar region for effective fixation with minimal risk of implant failure.

The main limitation of the study is that it is a single center study with a limited sample size and hence the study may not reflect the morphometric characteristics of lumbar vertebrae pedicles of the entire male adult Zimbabwean population.

Conclusion

Morphometric studies of pedicles of lumbar vertebrae shows variations in different ethnic groups and their detailed knowledge is crucial for successful pedicle screw fixation. A screw length of 40-45 $\mathrm{mm}$ should be used for lumbar transpedicular 
screw fixation with minimal risk of implant failure in Zimbabwean population.

\section{References}

1. Ayodeji SA, Deborah SA, Allen SA. X-raying of the Lumbar Spine. IJNPT. 2016; 2(4): 24-38. Doi: 10.11648/j.ijnpt.20160204.11

2. Ukunda UN, Lukhele MM. The posterior-only surgical approach in the treatment of tuberculosis of the spine: outcomes using cortical bone allografts. Bone Joint J. 2018; 100(9): 1208-13. Doi: 10.1302/0301620X.100B9.BJJ-2017-1326.R2

3. Chaturvedi A, Klionsky NB, Nadarajah U, Chaturvedi A, Meyers SP. Malformed vertebrae: a clinical and imaging review. Insights Imaging. 2018; 9(3): 343-55. Doi: 10.1007/s13244-018-0598-1

4. Mohanty SP, Kanhangad MP, Bhat SN, Chawla S. Morphometry of the lower thoracic and lumbar pedicles and its relevance in pedicle fixation. Musculoskelet Surg. 2018; 102(3): 299-305. Doi: 10.1007/s12306-018-0534-z

5. Scarone P, Vincenzo G, Distefano D, Del Grande F, Cianfoni A, Presilla $S$, et al. Use of the Airo mobile intraoperative CT system versus the O-arm for transpedicular screw fixation in the thoracic and lumbar spine: a retrospective cohort study of 263 patients. J Neurosurg: Spine. 2018; 29(4): 397-406. Doi: 10.3171/2018.1.SPINE17927

6. O'halloran D, Suh S, inventors; Globus Medical Inc, assignee. Methods and apparatus for treating vertebral fractures. United States patent US 10,537,368. 2020 Jan 21.

7. Macke JJ, Woo R, Varich L. Accuracy of robot-assisted pedicle screw placement for adolescent idiopathic scoliosis in the pediatric population. J Robot Surg. 2016; 10(2): 145-50. Doi: 10.1007/s11701-016-05877

8. Dayani F, Chen YR, Johnson E, Deb S, Wu Y, Pham L, et al. Minimally invasive lumbar pedicle screw fixation using cortical bone trajectory-Screw accuracy, complications, and learning curve in 100 screw placements. J Clin Neurosci. 2019; 61: 106-11. doi: 10.1016/j.jocn.2018.10.131

9. Abbas J, Peled N, Hershkovitz I, Hamoud K. Pedicle Morphometry Variations in Individuals with Degenerative Lumbar Spinal Stenosis. BioMed Res Int. 2020; 2020: $7125914 . \quad$ Doi: 10.1155/2020/7125914

10. Esfandiari H, Newell R, Anglin C, Street J, Hodgson AJ. A deep learning framework for segmentation and pose estimation of pedicle screw implants based on C-arm fluoroscopy. Int J Comput Assist Radiol Surg.
2018; 13(8): 1269-82. Doi: 10.1007/s11548-0181776-9

11. Gupta KK, Attri JP, Singh A, Kaur H, Kaur G. Basic concepts for sample size calculation: Critical step for any clinical trials! Saudi J Anaesth. 2016; 10(3): 32831. Doi: $10.4103 / 1658-354 X .174918$

12. Lopopolo RB. Cunningham's Manual of Practical Anatomy: Thorax and Abdomen. 2017; 2: 135-37. OUP Oxford

13. Singh R, Srivastva SK, Prasath CS, Rohilla RK, Siwach $R$, Magu NK. Morphometric measurements of cadaveric thoracic spine in Indian population and its clinical applications. Asian Spine J. 2011; 5(1): 20-34. Doi: 10.4184/asj.2011.5.1.20

14. Munusamy T, Thien A, Anthony MG, Bakthavachalam R, Dinesh SK. Computed tomographic morphometric analysis of cervical pedicles in a multi-ethnic Asian population and relevance to subaxial cervical pedicle screw fixation. European Spine J. 2015; 24(1): 120-6. Doi: 10.1007/s00586-014-3526-1

15. Bordes SJ, Tubbs RS. Lumbar Vertebrae. In Surgical Anatomy of the Lateral Transpsoas Approach to the Lumbar Spine 2020: (pp. 83-89). Elsevier.

16. Kim NH, Lee HM, Chung IH, Kim HJ, Kim SJ. Morphometric study of the pedicles of thoracic and lumbar vertebrae in Koreans. Spine. 1994; 19(12): 1390-4. Doi: 10.1097/00007632-199406000-00014

17. Zindrick MR, Wiltse LL, Doornik A, Widell EH, Knight GW, Patwardhan AG, et al. Analysis of the morphometric characteristics of the thoracic and lumbar pedicles. Spine. 1987; 12(2): 160-6. Doi: 10.1097/00007632-198703000-00012

18. Singel TC, Patel MM, Gohil DV. A study of width and height of lumbar pedicles in Saurashtra region. J Anat Soc India. 2004; 53(1): 4-9.

19. Amonoo-Kuofi HS. Age-related variations in the horizontal and vertical diameters of the pedicles of the lumbar spine. J Anat. 1995; 186(Pt 2): 321. PMID: 7649830

20. Tyagi S, Chhabra S, Narayan RK. Morphometric study of width and height of lumbar pedicles in population of Haryana. Int J Appl Dent Sci. 2017; 3(4): 78-81.

21. Krag MH, Weaver DL, Beynnon BD, Haugh LD. Morphometry of the thoracic and lumbar spine related to transpedicular screw placement for surgical spinal fixation. Spine. 1988; 13(1): 27-32. Doi: 10.1097/00007632-198801000-00007

22. Lien SB, Liou NH, Wu SS. Analysis of anatomic morphometry of the pedicles and the safe zone for through-pedicle procedures in the thoracic and lumbar spine. Eur Spine J. 2007; 16(8): 1215-22. Doi: 10.1007/s00586-006-0245-2

23. Kadioglu HH, Takci E, Levent A, Arik M, Aydin IH. Measurements of the lumbar pedicles in the Eastern 
Anatolian population. Surg Radiol Anat. 2003; 25(2): 120-6. Doi: 10.1007/s00276-003-0109-y

24. Kumar V, Mittal M. Morphometric study of pedicles of dried human lumbar vertebrae. IJHCR. 2020; 3(8): 30-4.
25. Gosal GS, Boparai A. A Prospective Study to Assess the Morphology of Pedicles of Lower Thoracic and Lumbar Vertebrae using Computerized Tomography Scan Measurements in North-Indian Population. Int J Sci Res. 2015; 4(5): 2935-6. 